\title{
Early life urban exposure as a risk factor for developing obesity and impaired fasting glucose in later adulthood: results from two cohorts in Thailand
}

Chaisiri Angkurawaranon ${ }^{1,2^{*}}$, Anawat Wisetborisut ${ }^{2}$, Kittipan Rerkasem ${ }^{3}$, Sam-ang Seubsman ${ }^{4,5}$, Adrian Sleigh ${ }^{5}$, Pat Doyle ${ }^{1}$ and Dorothea Nitsch ${ }^{1}$

\begin{abstract}
Background: Obesity and obesity related conditions, driven by processes such as urbanization and globalization, are contributing to pronounced cardiovascular morbidity and mortality in developing countries. There is limited evidence on the influence of living in an urban environment in early life on obesity and obesity related conditions later in life in developing countries such as Thailand.

Methods: We used data from two cohort studies conducted in Thailand, the Thai Cohort Study (TCS) and the Chiang Mai University (CMU) Health Worker Study, to investigate the association between early life urban (vs rural) exposure and the later development of obesity. We additionally explored the association between early life urban exposure and impaired fasting glucose in adulthood using data from the CMU Health Worker Study.

Results: Among 48,490 adults from the TCS, $9.1 \%$ developed obesity within 4 years of follow-up. Among 1,804 initially non-obese adults from CMU Health worker study, $13.6 \%$ developed obesity within 5 years of follow-up. Early life urban exposure was associated with increased risk of developing obesity in adulthood in both cohorts. Adjusting for age and sex, those who spent their early lives in urban areas were 1.21 times more likely to develop obesity in the TCS (OR 1.21, $95 \% \mathrm{Cl} 1.12$ to 1.31) and 1.65 times more likely in the CMU Health Worker study (OR 1.65, $95 \% \mathrm{Cl} 1.23$ to 2.20). These associations remained significant despite adjustment for later life urban exposure and current household income. No evidence for an association was found for impaired fasting glucose.

Conclusions: Early life urban exposure was associated with increased risk of developing obesity in adulthood. These findings support public health intervention programs to prevent obesity starting from early ages.
\end{abstract}

\section{Background}

The rapidly increasing prevalence of obesity and obesity related conditions such as impaired fasting glucose and diabetes, have been considered a worldwide phenomenon [1]. This is becoming a major issue in developing countries, where obesity and diabetes are now contributing to a pronounced cardiovascular morbidity and mortality [2-4].

\footnotetext{
* Correspondence: Chaisiri.angkurawaranon@lshtm.ac.uk; chaisiri.a@cmu.ac.th 'Department of Non-communicable Disease Epidemiology, Faculty of Epidemiology and Population Health, London School of Hygiene and Tropical Medicine, WC1E 7HT London, UK

2Department of Family Medicine, Faculty of Medicine, Chiang Mai University, Chiang Mai, Thailand

Full list of author information is available at the end of the article
}

Obesity and diabetes are considered to have early life origins [5]. Early life risk factors for childhood and adult obesity include maternal malnutrition, maternal obesity, low birth weight, high birth weight, rapid weight gain in the first year of life, and rapid linear growth in childhood [6-8]. In India, there is evidence that accelerated growth during childhood is linked with obesity, insulin resistance and diabetes later in life [9]. These early life risk factors may also be enhanced or modified by later life environmental influences [10].

Urbanization is linked with many of these early life risk factors $[11,12]$ and is considered one of the key environmental factors driving obesity and diabetes trends

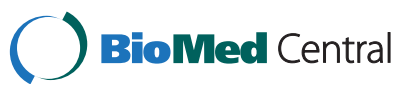

(C) 2015 Angkurawaranon et al. Open Access This article is distributed under the terms of the Creative Commons Attribution 4.0 International License (http://creativecommons.org/licenses/by/4.0/), which permits unrestricted use, distribution, and reproduction in any medium, provided you give appropriate credit to the original author(s) and the source, provide a link to the Creative Commons license, and indicate if changes were made. The Creative Commons Public Domain Dedication waiver (http://creativecommons.org/publicdomain/zero/1.0/) applies to the data made available in this article, unless otherwise stated. 
[13]. In developing countries, there is evidence that urbanization may increase the risk of obesity and diabetes through lower physical activity and unhealthy dietary habits such as high glucose consumption [14]. However, urbanization may also be associated with many factors that could decrease the later risk of obesity and diabetes, such as improved socioeconomic status leading to a healthier life style, and better access to care [15]. Compared to developed countries, the rate of urbanization has occurred more rapidly in developing countries [16].

Thailand is a country considered at a tipping point of transition towards becoming a developed country [17]. Obesity has doubled within previous decades [18]. A nationally representative survey in 2009 estimated that around $63.8 \%$ of Thai women and $49.7 \%$ of Thai men aged over 20 were obese $(\mathrm{BMI} \geq 25)$. The prevalence of diabetes in Thailand was around 8.1 and $6.4 \%$, amongst women and men respectively in 2009 [19]. The study also reported evidence that the prevalence of obesity and diabetes is higher in urban areas. At an ecological level we can thus link urban residence and obesity. A recent cross sectional study among adult healthcare workers in Thailand has also suggested that exposure to urban environments in early life (compared to rural environments) was associated with higher levels of body mass index and fasting glucose in adulthood [20]. However, to properly investigate the influence of early life urban environments on the development of obesity and obesity related conditions, a cohort study is required [21]. Such cohort studies are rare in Thailand. An understanding of the relationship between early life environments with later development of obesity could help identify appropriate targets and timing of interventions to help combat the burden of obesity in Thailand.

We aimed to investigate the association between early life urban exposure with later development of obesity in adulthood using two cohort studies conducted in Thailand between 2005 and 2013. This analysis will also explore whether early life urban exposure remained independently associated with obesity despite later accumulation of adulthood urban exposure. Using data from one of the cohort studies, we will further investigate the association between early life urban exposure with impaired fasting glucose in adulthood.

\section{Methods}

The study utilized data from two cohort studies conducted in Thailand, the Thai Cohort Study (TCS) and the Chiang Mai University (CMU) Health Worker Study.

\section{The cohort studies}

The Thai Cohort Study (TCS) is a cohort of students at the Sukhothai Thammathirat Open University in 2005. TCS enrolled 87,142 students residing all over Thailand.
The study represented the Thai population well in terms of the median age, gender, geographic and income distribution [22]. This cohort was followed up in 2009 [23]. Using a 20-page questionnaire, data was collected in seven major areas that include socio-demographic details, income and work, food and physical activity, tobacco and alcohol use. This included self-reported body weight and height at baseline and follow up (Fig. 1).

The Chiang Mai University (CMU) Health Worker Study surveyed health care workers at the Faculty of Medicine, Chiang Mai University and CMU hospital in 2008. CMU hospital, situated in an urban area of Chiang Mai province, is the largest teaching hospital in Northern Thailand. The study enrolled over 3,500 participants [24]. Self-reported demographic status, monthly income, risk behaviors and common chronic diseases such as hypertension and diabetes were collected using an online questionnaire. Subsequently, all workers were offered a physical examination as well as a complete blood count (CBC) and urine examination according to the Thai National guideline [25]. Other laboratory investigations (fasting glucose and lipid profiles) were only offered to those ages 35 or above. During examinations, standing height and weight were measured using a portable stadiometer and electronic scale. Blood samples were sent to the Central Laboratory Unit in the hospital for processing. The participants were followed up in 2013 [26]. On the day of examinations and laboratory investigations, face-to-face interviews were conducted to obtain a complete migration history from birth to current age (Fig. 2).

\section{Migration history and urban exposure definition}

The TCS used self-classification of urban-rural residence at three life course periods: early life at age 10-12; in 2005 (base line survey); and in 2009 (follow up survey). Participants were asked whether their permanent home during these three periods were considered 'countryside or city/town' [27].

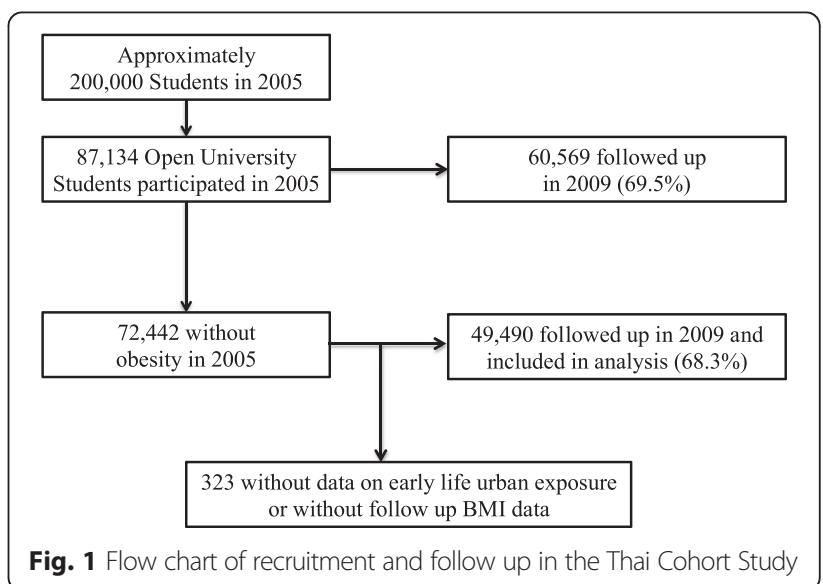




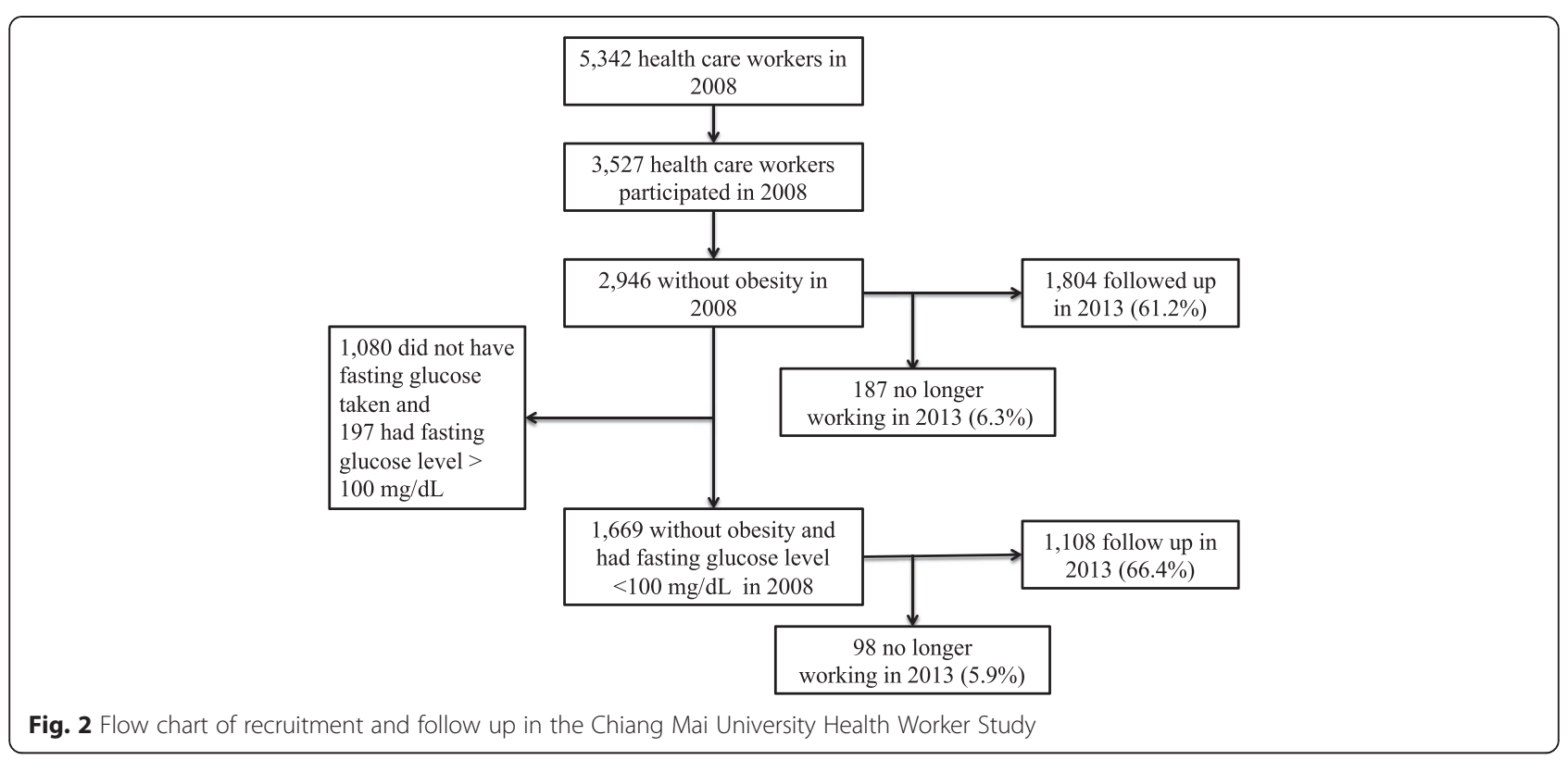

The CMU health worker study used an urban classification derived from the Thai urban hierarchy based on population density and the size of municipalities [28]. Urban residence was defined as living in any districts making up Bangkok and Chiang Mai Metropolitan Area. These districts consisted of Muang (Chiang Mai Province), Sarapi, Sanpatong, Hang Dong, Mae Rim, Sansai, Doi Saket, Mae On, Sang Kampang, Muang (Lumphun Province). All other districts in Chiang Mai and Lamphun province were classified as rural. Participants were asked about their entire migration history during their lifetime. District of residence at two life course periods, early life at age 5 and early adulthood at age 20, were determined through interviews.

\section{Outcome definitions}

For obesity, body mass index (BMI) was calculated using body weight (in kilograms) divided by height (in meters) squared. As suggested for Asian populations, obesity was defined as having a body mass index of $25 \mathrm{~kg} / \mathrm{m}^{2}$ and above [29]. The development of obesity in both cohorts were defined as those who were not obese in the baseline survey and having a BMI of at least $25 \mathrm{~kg} / \mathrm{m}^{2}$ in the follow up survey.

For impaired glucose and type 2 diabetes, data were only available from the CMU Health Worker study. Preliminary analysis showed that the 5-year incidence for type 2 diabetes (fasting blood glucose of at least $126 \mathrm{mg} / \mathrm{dL}$ ) was small $(<1 \%)$. A fasting glucose of at least $100 \mathrm{mg} / \mathrm{dl}$, which is the criteria for impaired fasting glucose [30], was used as the outcome of interest. The development of impaired fasting glucose was defined as having a fasting glucose of less than $100 \mathrm{mg} / \mathrm{dL}$ in 2008 and a fasting glucose level of at least $100 \mathrm{mg} / \mathrm{dl}$ in 2013 or taking medication for type 2 diabetes in 2013.

\section{Other variable of interests}

Socioeconomic status, which is considered a key mediator and/or confounder between urbanization and health outcomes [31], was measured through self reported household monthly income. This information was collected during the baseline survey and follow-up survey for both cohorts.

\section{Analysis strategy}

Data from each cohort were analyzed and presented separately. Participants who were pregnant at time of follow up were excluded from the analyses in both cohorts. Demographic data were stratified by gender for descriptive purposes. Demographic factors associated with early life urban residence were tested using chi-square or t-tests. Logistic regression was used to determine the association between early life urban residence and risk of developing obesity and impaired fasting glucose/diabetes. To determine whether early life urban exposure predicts the development of obesity independently of later adulthood urban exposure, further analysis were done adjusting for later urban exposures.

For the TCS, the association between early life urban exposure (at age 10-12) with obesity was further adjusted for urban exposure in 2005 (baseline) and in 2009 (follow up). Additional adjustments were done for current socioeconomic at follow up (in 2009).

For the CMU cohort study, the association between early life urban residence (at age 5) with obesity and impaired fasting glucose/diabetes was further adjusted for 
early adulthood urban exposure (at age 20). As all health care workers were already working and living in an urban area of Chiang Mai in 2008 (baseline survey), any further adjustments for later life exposure (after 20) would not provide additional information. Additional adjustments were also done for current socioeconomic status at follow up (in 2013). For development of impaired fasting glucose/diabetes, adjustments were also made for family history of type 2 diabetes.

We considered interactions between early life urban exposure and age and sex. In both cohorts, we did not find evidence for interactions between age or sex and early life urban exposure on incident obesity. Thus age and sex were considered as confounders in all final analyses. Potential mediators such as behavioural and lifestyle risk factors, concurrent disease status and current medication were considered to be on the causal pathways between early life urban exposure and development of obesity and impaired fasting glucose. These variables were not adjusted for in all analyses.

\section{Ethical approval}

Informed consent was obtained from all participants in both cohorts. The TCS was approved by the Sukhothai Thammathirat Open University Research and Development Institute (protocol 0522/10) and the Australian National University Human Research Ethics Committee (protocol 2004344). The CMU Health Worker study was approved by Ethical committees from the Faculty of Medicine, CMU (no. 069/2012) and London School of Hygiene and Tropical Medicine (ref. 6521).

\section{Results}

Follow up rates in TCS

In $2005,87,134$ students agreed to participate $(44.0 \%$ response). Using self-reported weight and height, 72,442 were not considered obese. In 2009, $68.3 \%(48,490)$ of non-obese participants were followed up with completed data for analysis (Fig. 1). The participants who were lost to follow up were younger compared to those followed up. However, for gender, baseline BMI, urbanicity of locations in early life and in 2005 , there were no obvious differences (Appendix 1).

\section{Follow up rates in CMU health worker study}

In 2008, 3,527 health care workers agreed to participate (66.0\% response). Of these participants, 2,946 were not considered obese. In 2013, $61.2 \%(1,804)$ of non-obese participants were followed up (Fig. 2). The participants who were lost to follow up were more likely to be male and slightly older compared to those who were followed up. However, the baseline BMI and fasting glucose level in 2008 did not differ between those followed up and loss to follow up (Appendix 2).

\section{Participant characteristics}

Demographic characteristics of participants in the TCS are displayed in Table 1, and those of the CMU Health Worker Study in Table 2. The average age of the TCS participants at baseline was 30.7 years $(s d=7.9)$, which was younger than CMU health worker study participants at baseline (average age 38.3, sd=8.6). Women represented the majority of both cohorts at 59.0 and $79.9 \%$ for TCS study and the CMU study respectively. For early life urban exposure, $25 \%$ of the TCS participants and over $50 \%$ of the CMU study participants spent their early life living in urban areas. For TCS, the proportion living in urban areas rose from $50.3 \%$ in 2005 to $54.8 \%$ in 2009 . By early adulthood (age 20), over $90 \%$ of the participants from the CMU study were living in urban areas.

Among the initially non-obese participants in the TCS, the baseline mean body mass index (BMI) in 2005 was $20.2 \mathrm{~kg} / \mathrm{m}^{2}$ for women and $21.6 \mathrm{~kg} / \mathrm{m}^{2}$ for men. By 2009 ,

Table 1 Distribution of demographic characteristics and risk of developing obesity among initially non-obese participants of the Thai Cohort Study

\begin{tabular}{|c|c|c|c|}
\hline Thai cohort study & $\begin{array}{l}\text { Female } \\
(N=28,635)\end{array}$ & $\begin{array}{l}\text { Male } \\
(N=19,855)\end{array}$ & $\begin{array}{l}\text { Total } \\
(48,490)\end{array}$ \\
\hline Mean age in 2005 (sd) & $29.6(7.4)$ & $32.2(8.4)$ & $30.7(7.9)$ \\
\hline \multicolumn{4}{|l|}{$\begin{array}{l}\text { Monthly household income } \\
\text { in 2009: (\%:n) }\end{array}$} \\
\hline$<10,000$ baht & $22.1(6333)$ & $22.5(4461)$ & $22.3(10.794)$ \\
\hline $10,000-20,000$ baht & $24.6(7046)$ & $24.7(4902)$ & $24.6(11,948)$ \\
\hline 20,000-50,000 baht & $38.4(10,985)$ & 39.2 (7792) & $38.7(18,777)$ \\
\hline$>50,000$ baht & $13.4(3842)$ & $11.4(2255)$ & $12.6(6097)$ \\
\hline Missing & $1.5(429)$ & $2,2(445)$ & $1.8(874)$ \\
\hline \multicolumn{4}{|l|}{$\begin{array}{l}\text { Early life location at } \\
\text { age 10-12: }(\%, n)\end{array}$} \\
\hline Rural & $74.6(21,373)$ & $79.2(15,731)$ & $76.5(37,104)$ \\
\hline Urban & $25.4(7262)$ & $20.8(4124)$ & $23.5(11,386)$ \\
\hline \multicolumn{4}{|l|}{ Residence in $2005(\%, \mathrm{n})$} \\
\hline Rural & $48.0(13,753)$ & $51.6(10,235)$ & $49.5(23,988)$ \\
\hline Urban & $51.8(14,8219)$ & $48.2(9,575)$ & $50.3(24,394)$ \\
\hline Missing & $0.2(63)$ & $0.2(45)$ & $0.2(108)$ \\
\hline \multicolumn{4}{|l|}{ Residence in $2009(\%, n)$} \\
\hline Rural & $42.1(12,059)$ & $46.8(92,823)$ & $44.0(21,341)$ \\
\hline Urban & $56.6(16,209)$ & $52.2(10,371)$ & $54.8(26,580)$ \\
\hline Missing & $1.3(367)$ & $1.0(202)$ & $1.2(569)$ \\
\hline BMI in 2005 (mean, sd) & $20.2(2.1)$ & $21.6(2.0)$ & $20.8(2.2)$ \\
\hline BMI in 2009 (mean, sd) & $21.0(2.6)$ & $22.4(2.3)$ & $21.6(2.6)$ \\
\hline Increase in BMI (mean, sd) & $0.84(1.6)$ & $0.75(1.5)$ & $0.80(1.6)$ \\
\hline $\begin{array}{l}\text { Developed obesity } \\
(\mathrm{BMl} \geq 25) \text { by } 2009(\%, \mathrm{n})\end{array}$ & $7.3(2077)$ & $11.8(2346)$ & $9.1(4423)$ \\
\hline
\end{tabular}

$B M I$ body mass index in $\mathrm{kg} / \mathrm{m} 2$ 
Table 2 Distribution of demographic characteristics and risk of developing obesity and impaired fasting glucose/diabetes among initially non-obese participants of Chiang Mai University Health Worker Study

\begin{tabular}{|c|c|c|c|}
\hline CMU health worker study & $\begin{array}{l}\text { Female } \\
(N=1443)\end{array}$ & $\begin{array}{l}\text { Male } \\
(N=361)\end{array}$ & $\begin{array}{l}\text { Total } \\
(1804) \\
\end{array}$ \\
\hline Mean age in 2008 (sd) & $38.4(8.6)$ & $38.1(8.3)$ & $38.3(8.6)$ \\
\hline \multicolumn{4}{|l|}{$\begin{array}{l}\text { Monthly household income } \\
\text { in 2013: (\%:n) }\end{array}$} \\
\hline$<10,000$ baht & $7.7(111)$ & $19.9(72)$ & $10.2(183)$ \\
\hline $10,000-20,000$ baht & $20.0(288)$ & $36.3(131)$ & $23.2(419)$ \\
\hline 20,000-50,000 baht & $41.4(598)$ & $27.4(99)$ & $38.6(697)$ \\
\hline$>50,000$ baht & $30.9(446)$ & $16.3(59)$ & $28.0(505)$ \\
\hline \multicolumn{4}{|l|}{$\begin{array}{l}\text { Early life location at } \\
\text { age } 5:(\%, n)\end{array}$} \\
\hline Rural & $44.0(635)$ & $29.1(105)$ & $41.0(740)$ \\
\hline Urban & $56.0(808)$ & $70.9(256)$ & $59.0(1,064)$ \\
\hline \multicolumn{4}{|l|}{$\begin{array}{l}\text { Early adulthood location at } \\
\text { age } 20(\%, n)\end{array}$} \\
\hline Rural & $9.8(141)$ & $7.8(28)$ & $9.4(169)$ \\
\hline Urban & $90.0(1,302)$ & $92.2(333)$ & $90.6(1,635)$ \\
\hline BMI in 2008 (mean, sd) & $21.3(2.2)$ & $22.8(2.0)$ & $21.6(2.2)$ \\
\hline BMI in 2013 (mean, sd) & $22.7(2.9)$ & $23.9(2.5)$ & $22.9(2.9)$ \\
\hline Increase in BMI (mean, sd) & $1.38(1.9)$ & $1.10(1.8)$ & $1.32(1.9)$ \\
\hline $\begin{array}{l}\text { Developed obesity } \\
(\text { BMI } \geq 25) \text { by } 2009(\%, n)\end{array}$ & $12.8(185)$ & $16.6(60)$ & $13.6(245)$ \\
\hline $\begin{array}{l}\text { Fasting glucose in } 2008^{a} \\
\text { (mean, sd) }\end{array}$ & $84.5(8.9)$ & $87.2(9.2)$ & $85.0(9.0)$ \\
\hline $\begin{array}{l}\text { Fasting glucose in } 2013^{\mathrm{a}} \\
\text { (mean, sd) }\end{array}$ & $90.1(8.4)$ & $94.7(12.6)$ & $91.1(9.6)$ \\
\hline $\begin{array}{l}\text { Increase in fasting glucose }{ }^{a} \\
\text { (mean, sd) }\end{array}$ & $5.63(9.9)$ & $7.53(12.4)$ & $6.03(10.5)$ \\
\hline $\begin{array}{l}\text { Developed impaired fasting } \\
\text { glucose/diabetes }{ }^{a}(\%, n)\end{array}$ & $8.6(76)$ & $20.2(45)$ & $10.9(121)$ \\
\hline
\end{tabular}

the average increase in BMI for women was $0.84 \mathrm{~kg} / \mathrm{m}^{2}$ and $0.75 \mathrm{~kg} / \mathrm{m}^{2}$ for men. The risk of developing obesity was 7.3 in women and $11.8 \%$ in men (Table 1). As participants from the CMU study were older, the baseline BMI and risks of developing obesity were higher than those of the TCS study. Among the initially non-obese participants in the CMU study, the baseline mean body mass index (BMI) in 2008 was $21.3 \mathrm{~kg} / \mathrm{m}^{2}$ for women and $22.8 \mathrm{~kg} / \mathrm{m}^{2}$ for men. By 2013, the average increase in BMI for women was $1.38 \mathrm{~kg} / \mathrm{m}^{2}$ and $1.10 \mathrm{~kg} / \mathrm{m}^{2}$ for men. The risk of developing obesity over the follow-up period was 12.8 in women and $16.6 \%$ in men (Table 2).

\section{Distribution of potential confounders}

In the TCS, those who lived in an urban areas at age 10-12 were more likely to be older, female and have higher income at follow up in 2009 compared to those who lived in a rural areas at age 10-12. For CMU Health Worker study, those who lived in an urban area at age 5 were more likely to be older, male and have lower income at follow up in 2013 compared to those who spent their early life in rural residences (Table 3 ).

\section{Early life urban exposure as a risk factor for developing obesity}

There was consistent evidence from both cohorts that among initially non-obese participants, exposure to urban environments in early life was associated with the later development of obesity in adulthood. Adjusting for age, sex and baseline BMI, those who spent their early life in an urban area were 1.16 times more likely to develop obesity in the TCS (OR 1.16, $95 \%$ CI 1.07 to 1.26 ) and 1.43 times more likely in the CMU Health Worker study (OR 1.43, 95 \% CI 1.01 to 2.02). Adjustment for later adulthood urban residence and current socioeconomic status attenuated these effects. After adjustment for age, sex, later adulthood urban exposure and current socioeconomic status, those spending their early life in an urban area were 1.14 times more likely to develop obesity in the TCS (OR 1.14, $95 \%$ CI 1.04 to 1.24) and 1.44 times more likely in the CMU Health Worker Study (OR 1.46, $95 \%$ CI 0.97 to 2.13) (Table 4). Later adulthood urban exposure in 2009 was also weakly associated with the risk of development of obesity in the TCS (OR 1.10, 95 \% CI 1.00 to 1.21) while later adulthood urban exposure at age 20 was not associated with increased risk of developing obesity in the CMU Health Worker study (OR 0.95, $95 \%$ CI 0.49 to 1.82). (Appendix 3).

\section{Early life urban exposure as a risk factor for developing impaired fasting glucose}

After adjustment for age, sex and family history of type 2 diabetes, we did not find evidence that exposure to urban environments in early life was associated with development of impaired fasting glucose in the CMU study population (OR $0.91,0.43$ to 1.89). The association between early life urban exposure and development of impaired fasting glucose did not materially alter with additional adjustments for later adulthood urban exposure at age 20 and current socioeconomic status (OR $0.74,95 \%$ CI 0.31 to 1.78 ) (Table 5 ).

\section{Discussion}

We found consistent evidence from two cohorts that among initially non-obese Thai adults, exposure to an urban environment in early life was associated with increased risk of obesity in adulthood. No evidence was 
Table 3 Demographic factors, BMI and fasting glucose by early life urban residence

\begin{tabular}{|c|c|c|c|c|c|c|}
\hline & CMU health $w$ & er study & & Thai Cohort Stud & (CS) & \\
\hline & Early life resid & e at age 5 & & Early life residenc & t age $10-12$ & \\
\hline & Rural $n=740$ & Urban $n=1064$ & $P$-value & Rural $n=37,105$ & Urban $n=11,385$ & $P$-value \\
\hline Mean age at baseline (sd) & $37.2(8.5)$ & $39.1(8.5)$ & $<0.01$ & $30.3(7.7)$ & $31.8(8.6)$ & $<0.01$ \\
\hline Sex: $(\operatorname{col} \%, n)$ & & & $<0.01$ & & & $<0.01$ \\
\hline Female & 85.8 & 75.9 & & 57.6 & 63.8. & \\
\hline Male & 14.2 & 24.1 & & 42.4 & 36.2 & \\
\hline household income at follow up (col \%, n) & & & $<0.01$ & & & $<0.01$ \\
\hline$<10,000$ baht & 6.9 & 12.4 & & 25.7 & 11.1 & \\
\hline $10,000-20,000$ baht & 15.1 & 28.9 & & 26.3 & 19.4 & \\
\hline 20,000-50,000 baht & 45.0 & 34.2 & & 37.3 & 43.2 & \\
\hline$>50,000$ baht & 33.0 & 24.5 & & 8,9 & 24.6 & \\
\hline Missing & 0.0 & 0.0 & & 1.8 & 1.7 & \\
\hline Mean BMl at baseline (sd) & $21.3(2.2)$ & $21.8(2.2)$ & $<0.01$ & $20.8(2.2)$ & $20.8(2.2)$ & 0.14 \\
\hline Mean BMI at follow up (sd) & $22.6(2.8)$ & $23.2(2.9)$ & $<0.01$ & $21.5(2.5)$ & $21.6(2.6)$ & $<0.01$ \\
\hline Mean increase in BMI (sd) & $1.34(1.8)$ & $1.31(1.9)$ & 0.73 & $0.80(1.6)$ & $0.84(1.6)$ & 0.01 \\
\hline Mean fasting glucose in 2008 (sd) & $83.7(8.5)$ & $84.0(7.7)$ & 0.53 & Not available & & \\
\hline Mean fasting glucose in 2013 (sd) & $89.7(8.8)$ & $90.7(9.1)$ & 0.07 & Not available & & \\
\hline Increase in fasting glucose (sd) & $6.0(9.9)$ & $6.7(10.0)$ & 0.26 & Not available & & \\
\hline
\end{tabular}

BMI at baseline was in 2008 for CMU Health worker study and 2005 for TCS; BMI at follow up was in 2013 for CMU Health Worker study and 2009 for TCS. 32 baht is approximately 1 US dollar; For fasting glucose $\mathrm{N}$ for early rural $=429$, early urban $=679$. Unit for BMl in $\mathrm{kg} / \mathrm{m}^{2}, \mathrm{Unit}$ for fasting glucose in mg/dL

found for an association between early life urban exposure and the development of impaired fasting glucose.

It is important to acknowledge the strengths and limitations of the study before further discussion and interpretations can be made. This study utilized data from two cohort studies which were set up to investigate the role of urbanization and the development of non-communicable diseases (NCDs) in Thailand. Some systematic differences between responders and non-responders were observed but these groups did not differ by baseline BMI and fasting glucose level in the CMU Health worker study, or by

Table 4 Early life urban exposure and risk of developing obesity in adulthood

\begin{tabular}{llll} 
& Model 1 & Model 2 & Model 3 \\
\% (n) obese by follow-up & $\begin{array}{l}\text { Adjusted OR for obesity } \\
(95 \% \mathrm{Cl}) \text { and } p \text {-value }\end{array}$ & $\begin{array}{l}\text { Adjusted OR for obesity } \\
(95 \% \mathrm{Cl}) \text { and } p \text {-value }\end{array}$ & $\begin{array}{l}\text { Adjusted OR for obesity } \\
(95 \% \mathrm{Cl}) \text { and } p \text {-value }\end{array}$ \\
\hline
\end{tabular}

CMU health worker study:

Early life residence at age 5

$\begin{array}{lllll}\text { Rural }(n=740) & 10.3(76) & \text { Reference } & \text { Reference } & \text { Reference } \\ \text { Urban }(n=1,065) & 15.9(169) & 1.43(1.01 \text { to } 2.02) p=0.04 & 1.45 \text { (1.00 to 2.22) } p=0.05 & 1.44 \text { (0.97 to 2.13) } p=0.07\end{array}$

Thai Cohort Study (TCS):

Early life residence at age 10-12

\begin{tabular}{lllll} 
Rural $(n=37,105)$ & $8.8(3,251)$ & Reference & Reference & Reference \\
Urban $(n=11,385)$ & $10.3(1,172)$ & $1.16(1.07$ to 1.26$) p<0.01$ & $1.13(1.04$ to 1.23$) p<0.01$ & $1.14(1.04$ to 1.24$) p<0.01$ \\
\hline
\end{tabular}

BMI at baseline was in 2008 for CMU Health worker study and 2005 for TCS; BMI at follow up was in 2013 for CMU Health Worker study and 2009 for TCS. Obesity defined as $\mathrm{BMI} \geq 25 \mathrm{~kg} / \mathrm{m}^{2}$

Model 1 adjusted odds ratio (OR) for age, sex, baseline BMI

Model 2 adjusted odds ratio for age, sex, baseline BMI and later urban exposure in adulthood; Results from CMU Health worker study was adjusted for urban residence at age 20, Results from TCS adjusted for urban residence in 2005 and 2009

Model 3 Adjusted odds ration for age, sex, baseline BMI later urban exposure (same as model 2) and current household income at follow up

No evidence for interactions between early life urban residence and sex in both cohorts 
Table 5 Early life urban exposure and risk of developing impaired fasting glucose/diabetes in adulthood (Fasting Blood glucose $\geq 100 \mathrm{gm} / \mathrm{dL}$ )

\begin{tabular}{|c|c|c|c|c|}
\hline & & Model 1 & Model 2 & Model 3 \\
\hline CMU health worker study: & $\begin{array}{l}\%(n) \text { with impaired } \\
\text { glucose by follow-up }\end{array}$ & $\begin{array}{l}\text { Adjusted OR for impaired } \\
\text { glucose }(95 \% \mathrm{Cl}) \text { and } p \text {-value }\end{array}$ & $\begin{array}{l}\text { Adjusted OR for impaired } \\
\text { glucose }(95 \% \mathrm{Cl}) \text { and } p \text {-value }\end{array}$ & $\begin{array}{l}\text { Adjusted OR for impaired } \\
\text { glucose }(95 \% \mathrm{Cl}) \text { and } p \text {-value }\end{array}$ \\
\hline \multicolumn{5}{|l|}{ Early Life Residence at age 5} \\
\hline Rural $(n=429)$ & $10.6 \%(45)$ & Reference & Reference & Reference \\
\hline Urban $(n=679)$ & $11.2 \%(76)$ & $0.91(0.43$ to 1.90$) 0.80$ & 1.01 (0.45 to 2.26) 0.99 & $0.74(0.31$ to 1.78$) 0.50$ \\
\hline
\end{tabular}

Fasting glucose at baseline measured in 2008 and followed up was in 2013 in Chiang Mai University (CMU) Health Worker Study

Model 1 adjusted odds ratio (OR) for age, sex, and family history of diabetes

Model 2 adjusted odds ratio for age, sex, family history of diabetes and later urban exposure in adulthood at age 20

Model 3 Adjusted odds ration for age, sex, family history of diabetes, later urban exposure in adulthood at age 20 and current household income at follow up in 2013

No evidence for interactions between early life urban residence and sex

baseline BMI and early life urban exposure in the TCS. The definition of urban exposure in both cohorts may be prone to misclassification bias. However, since only limited districts could be considered urban in the CMU Health worker study, urban exposure was unlikely to be misclassified. For TCS, self reported urban classification of residence has been shown to be associated with many aspects of urban living such as higher income, possession of cars and modern household appliances [32]. TCS used self-reported body weight and height to obtain the participant's BMI, which may also be prone to information bias. However, TCS has conducted a small validation study on these self-reported body weight and height measurements and found that the small discrepancies did not alter any of the associations between health behavior and body mass index [33]. Moreover, using self reported weight and height, the specificity for diagnosis of obesity $(B M I \geq 25)$ was over $97 \%$ with a positive predictive value of $94 \%$ amongst TCS participants [34]. Although not considered major issues, these imprecise measurements of urban exposures and BMI would be likely to underestimate the associations seen, rather than overestimate them. While we excluded women who were currently pregnant from our analyses, we could not fully exclude the potential effect from postpartum weight retention since we did not record pregnancies between follow up periods. However, given the consistency of the findings in two separate cohorts of different demographics, this was unlikely to be a major issue in our study.

The two cohorts offered different strengths. The cohort composition of TCS suggests that the results are likely to be generalizable to the Thai population [22]. While results from the CMU health worker study may not be generalizable to the Thai population, it offers a unique opportunity to control for some elements of urbanization that may be difficult to disentangle in TCS [26]. The CMU health worker study was restricted to a population with similar access to health services, employment, and similar living and working conditions.

Obesity and diabetes have early life origins that track into adulthood [5]. Urbanization is one of the key drivers linked with childhood obesity [35]. Studies have suggested that BMI in early life is associated with persistently higher BMI in adulthood [36], which in turn is associated with diabetes [37]. The socio-cultural environment associated with urbanization differs between countries, making direct comparison with other settings or populations difficult [38]. However, the results seen in this study are consistent with other studies from developing countries using a life course approach. Lifetime urban exposure was associated obesity and diabetes in Cameroon [13] and increasing BMI and fasting glucose in India [31]. Similar to our study, the associations seen were independent of age, current level of physical activity, and current socioeconomic status and residence.

This study provides evidence that non-obese young adults who had lived in an urban environment in their early life were at increased risk of developing obesity later on in adulthood compared to young adults who had not lived in an urban environment in early life. Although not considered obese at baseline, those with early life urban residence had slightly higher baseline BMI than those without, indicating that the progression to later obesity had already begun. Since most sociocultural and environmental influences associated with urbanization were controlled for in the CMU Health Worker Study, the main mediator for the association is thus likely to be lifestyle influences. Evidence from another study using TCS data suggested that those spending their early lives (at age 10-12) in urban areas were less likely to engaged in regular activity, and more likely to have unhealthy diets in adulthood, than those spending their early life in rural areas [32].

We found no evidence for an association between early life urban exposure and development of impaired 
fasting glucose in the CMU Health worker study. The risk of developing impaired fasting glucose was low in our study. Moreover, underlying disease conditions may influence other medication use and changes in lifestyles, which can ultimately affect weight gain and glucose homeostasis. Our study was underpowered to detect such associations and potential complexities. A longer duration of follow up and larger sample size is required. However, there are also a number of other plausible reasons why we could not detect an association between early life urban exposure and development of impaired fasting glucose. Since $90 \%$ of participants had been living in an urban area since age 20, there was likely to be a convergence of risks due to similar exposures to social and environmental factors, as seen in India [39]. Any differences due to early life urban exposure could be diluted if these biological risks (such as glucose level) were associated with more current or recent exposures rather than exposure in early life. Unlike BMI, fasting glucose has large biological variability and is more likely to reflect the current glucose homoeostasis [40]. It is also considered to be more susceptible to recent or current lifestyle habits and interventions [41, 42]. In a US study, a three- year history of weight gain among pre-obese adults was found not to result in higher levels of glucose compared to those who had maintain their weight [43]. Another possible explanation why our study could not detect an association between early life urban exposure and development of impaired fasting glucose was that the effect of urban environments may not be consistent across all health outcomes [31]. In some developing countries, including Thailand, while urbanization was associated with higher BMI and blood pressure, it was not always concurrently associated with higher lipid and glucose level $[44,45]$.

\section{Conclusions}

Consistent evidence from two cohorts found that early life urban exposure was associated with increase risk of developing obesity in adulthood. There are multiple underlying factors driving the association between urbanization and obesity, including maternal conditions, socio-environmental factors, and individual lifestyles [46, 47]. In this study, lifestyle or behavioural factors and access to care are likely to be the key drivers, but further research is needed to understand the factors and mediators underlying the link between early life urban exposure and risk of obesity in Thailand [48]. As already supported by previous research [49], there are benefits to delaying the onset of obesity in order to prevent diabetes and other conditions. Public health intervention programs should be implemented to halt the development of obesity in children and young adults in Thailand.

\section{Appendix 1}

Table 6 Demographic characteristics and baseline BMI in responders and non-responders of the Thai Cohort Study (TCS)

\begin{tabular}{|c|c|c|c|}
\hline & & $\begin{array}{l}\text { Followed up in } \\
2009(\mathrm{~N}=49,813)\end{array}$ & $\begin{array}{l}\text { Loss follow up in } \\
2009(\mathrm{~N}=22,629)\end{array}$ \\
\hline \multirow[t]{2}{*}{ Sex } & Female: n(\%) & $29,371(59.0)$ & $13,055(57.8)$ \\
\hline & Male: n(\%) & $20,442(41.0)$ & $9,573(42.3)$ \\
\hline \multirow[t]{2}{*}{ Age } & $\begin{array}{l}\text { Mean age in } 2005 \\
\text { among female (sd) }\end{array}$ & $29.7(7.4)$ & $26.2(6.1)$ \\
\hline & $\begin{array}{l}\text { Mean age in } 2005 \\
\text { years among male (sd) }\end{array}$ & $32.3(8.5)$ & $28.4(7.4)$ \\
\hline \multirow[t]{2}{*}{$\begin{array}{l}\mathrm{BMl} \text { in } \\
\mathrm{kg} / \mathrm{m}^{2}\end{array}$} & $\begin{array}{l}\text { Mean BMI in } 2005 \\
\text { among female (sd) }\end{array}$ & $20.2(2.1)$ & $19.9(2.0)$ \\
\hline & $\begin{array}{l}\text { Mean BMI in } 2005 \\
\text { among male (sd) }\end{array}$ & $21.6(2.0)$ & $21.3(2.0)$ \\
\hline \multirow{2}{*}{$\begin{array}{l}\text { Location at } \\
\text { age } 10-12\end{array}$} & Rural & $37,757(76.5)$ & 17,586 (78.6) \\
\hline & Urban & $11,601(23.5)$ & $4,791(21.4)$ \\
\hline \multirow{2}{*}{$\begin{array}{l}\text { Location in } \\
2005\end{array}$} & Rural & $24,550(49.6)$ & $10,649(47.5)$ \\
\hline & Urban & $24,934(50.4)$ & $11,790(52.5)$ \\
\hline
\end{tabular}

\section{Appendix 2}

Table 7 Demographic characteristics and baseline BMI and fasting glucose in responders and non-responders of the Chiang Mai University (CMU) Health Worker Study

\begin{tabular}{|c|c|c|c|}
\hline & & $\begin{array}{l}\text { Followed up } \\
\text { in } 2013 \\
(N=1,804)\end{array}$ & $\begin{array}{l}\text { Loss follow } \\
\text { up in } 2013 \\
(N=1,142)\end{array}$ \\
\hline \multirow[t]{2}{*}{ Sex } & Female: n(\%) & 1,441 (79.9) & 757 (66.3) \\
\hline & Male: n(\%) & $363(20.1)$ & $385(33.7)$ \\
\hline \multirow[t]{2}{*}{ Age } & $\begin{array}{l}\text { Mean age in } 2008 \text { among } \\
\text { female (sd) }\end{array}$ & 38.4 (8.6) & $41.4(9.5)$ \\
\hline & $\begin{array}{l}\text { Mean age in } 2008 \text { years } \\
\text { among male (sd) }\end{array}$ & $38.2(8.4)$ & $42.3(9.7)$ \\
\hline \multirow[t]{2}{*}{$\begin{array}{l}\mathrm{BMl} \text { in } \\
\mathrm{kg} / \mathrm{m}^{2}\end{array}$} & $\begin{array}{l}\text { Mean BMI in } 2008 \text { among } \\
\text { female (sd) }\end{array}$ & $21.3(2.2)$ & $21.4(2.3)$ \\
\hline & $\begin{array}{l}\text { Mean BMl in } 2008 \text { among } \\
\text { male (sd) }\end{array}$ & $22.8(2.0)$ & $22.8(1.9)$ \\
\hline \multirow[t]{2}{*}{$\begin{array}{l}\text { Fasting glucose } \\
\text { in } \mathrm{mg} / \mathrm{dL}\end{array}$} & $\begin{array}{l}\text { Mean fasting glucose in } \\
2009 \text { among female* }(\mathrm{sd})\end{array}$ & $84.5(8.9)$ & $85.3(9.4)$ \\
\hline & $\begin{array}{l}\text { Mean fasting glucose in } \\
2008 \text { among male** (sd) }\end{array}$ & $87.1(9.2)$ & $88.1(9.9)$ \\
\hline
\end{tabular}

Number of female with fasting glucose measurements followed up $=946$, lost follow up $=409$; number of male with fasting glucose measurement follow up $=249$, lost to follow up 189 


\section{Appendix 3}

Table 8 Early life urban exposure and risk of developing obesity in adulthood

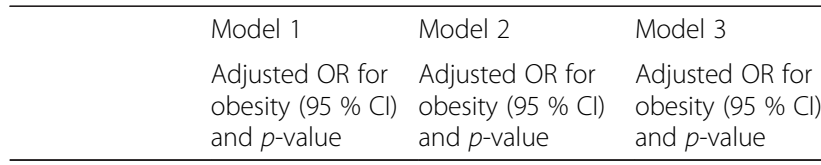

CMU Health

Worker study:

Early Life

Residence at

age 5

Rural

Urban

Reference

Reference

Reference

1.43 (1.01 to 2.02$) \quad 1.45$ (1.00 to 2.22$) \quad 1.44$ (0.97 to 2.13 )

$$
p=0.04 \quad p=0.05 \quad p=0.07
$$

Residence at

age 20

Rural

$-$

Reference

Reference

Urban

$-$

0.91 (0.48 to 1.74) 0.95 (0.49 to 1.82 )

$$
p=0.79 \quad p=0.87
$$

Thai Cohort

Study (TCS):

Early Life

Residence at

age 10-12

$\begin{array}{llll}\text { Rural } & \text { Reference } & \text { Reference } & \text { Reference } \\ \text { Urban } & 1.16(1.13 \text { to } 1.30) & 1.13(1.12 \text { to } 1.31) & 1.12(1.09 \text { to } 1.28) \\ & p<0.01 & p<0.01 & p=0.01\end{array}$

Residence

in 2005

$\begin{array}{llll}\text { Rural } & - & \text { Reference } & \text { Reference } \\ \text { Urban } \quad- & 0.99(0.90 \text { to } 1.08) & 0.98(0.89 \text { to 1.08) } \\ & p=0.81 & p=0.66\end{array}$

Residence

\begin{tabular}{|c|c|c|c|}
\hline Rural & - & Reference & Reference \\
\hline Urban & - & $\begin{array}{l}1.09 \text { (0.99 to } 1.20) \\
p=0.07\end{array}$ & $\begin{array}{l}1.10(1.00 \text { to } 1.21) \\
p=0.05\end{array}$ \\
\hline
\end{tabular}

in 2009

BMI at baseline was in 2008 for CMU Health worker study and 2005 for TCS; BMI at follow up was in 2013 for CMU Health Worker study and 2009 for TCS. Obesity defined as $\mathrm{BMI} \geq 25 \mathrm{~kg} / \mathrm{m}^{2}$

Model 1 adjusted odds ratio (OR) for age, sex, baseline BMI

Model 2 adjusted odds ratio for age, sex, baseline BMI and later urban exposure in adulthood; Results from CMU Health worker study was adjusted for urban residence at age 20, Results from TCS adjusted for urban residence in 2005 and 2009

Model 3 Adjusted odds ration for age, sex, baseline BMI later urban exposure (same as model 2) and current household income at follow up

\section{Competing interests}

The authors declare that they have no competing interests.

\section{Authors' contributions}

CA, PD, DN were responsible for the conception of the study. SS and AS were responsible for the design and acquisition of data for the TCS study. CA, AW, PD, DN were responsible for the design and acquisition of data for the CMU health worker study. CA analyzed the data and wrote the first draft of the manuscript. All authors contributed to interpretation of the data, revised the manuscript and approved the final manuscript.

\section{Acknowledgements}

Chiang Mai University Health Worker Study was funded by Faculty of Medicine Research Fund, Chiang Mai University. CA is supported by the Staff Development Fund, Chiang Mai University, Thailand. The Thai Cohort Study is funded by the International Collaborative Research Grants Scheme with joint grants from the Wellcome Trust UK (GR071587MA) and the Australian National Health and Medical Research Council (NHMRC) (268055) and global health grant from the NHMRC (585426). The authors would like to thank all the local staff of the Chiang Mai University and Sukhothai Thammathirat Open University and all participants who took part in both cohorts.

\section{Author details}

${ }^{1}$ Department of Non-communicable Disease Epidemiology, Faculty of Epidemiology and Population Health, London School of Hygiene and Tropical Medicine, WC1E 7HT London, UK. ²Department of Family Medicine, Faculty of Medicine, Chiang Mai University, Chiang Mai, Thailand.

${ }^{3}$ Department of Surgery, Faculty of Medicine, Chiang Mai University, Chiang Mai, Thailand. ${ }^{4}$ Faculty of Human Ecology, Sukhothai Thammathirat Open University, Nonthaburi, Thailand. ${ }^{5}$ National Centre for Epidemiology and Population Health, Australian National University, Canberra, ACT, Australia.

Received: 9 March 2015 Accepted: 3 September 2015 Published online: 16 September 2015

\section{References}

1. Caballero B. The global epidemic of obesity: an overview. Epidemiol Rev. 2007;29(1):1-5.

2. Nathan DM, Davidson MB, DeFronzo RA, Heine RJ, Henry RR, Pratley R, et al. Impaired fasting glucose and impaired glucose tolerance: implications for care. Diabetes Care. 2007;30(3):753-9.

3. Chen L, Magliano DJ, Zimmet PZ. The worldwide epidemiology of type 2 diabetes mellitus - present and future perspectives. Nat Rev Endocrinol. 2011;8(4):228-36.

4. Hossain P, Kawar B, El Nahas M. Obesity and diabetes in the developing world, a growing challenge. N Engl J Med. 2007;356(3):213-5.

5. Gluckman PD, Hanson MA, Cooper C, Thornburg KL. Effect of in utero and early-life conditions on adult health and disease. N Engl J Med. 2008;359(1):61-73

6. Reilly JJ, Armstrong J, Dorosty AR, Emmett PM, Ness A, Rogers I, et al. Early life risk factors for obesity in childhood: cohort study. BMJ. 2005;330(7504):1357.

7. Parsons TJ, Power C, Manor O. Fetal and early life growth and body mass index from birth to early adulthood in 1958 British cohort: longitudinal study. BMJ. 2001;323(7325):1331-5.

8. Leong NM, Mignone LI, Newcomb PA, Titus-Ernstoff L, Baron JA, TrenthamDietz A, et al. Early life risk factors in cancer: the relation of birth weight to adult obesity. Int J Cancer. 2003;103(6):789-91.

9. Yajnik CS. Early life origins of insulin resistance and type 2 diabetes in India and other Asian countries. J Nutr. 2004;134(1):205-10

10. Hu FB. Globalization of diabetes the role of diet, lifestyle, and genes. Diabetes Care. 2011;34(6):1249-57.

11. Hillemeier MM, Weisman CS, Chase GA, Dyer A-M. Individual and community predictors of preterm birth and Low birthweight along the rural-urban continuum in central Pennsylvania. J Rural Health. 2007;23(1):42-8

12. Jain $V$, Singhal A. Catch up growth in low birth weight infants: striking a healthy balance. Rev Endocr Metab Disord. 2012;13(2):141-7.

13. Sobngwi E, Mbanya J-C, Unwin NC, Porcher R, Kengne A-P, Fezeu $L$, et al. Exposure over the life course to an urban environment and its relation with obesity, diabetes, and hypertension in rural and urban Cameroon. Int J Epidemiol. 2004:33(4):769-76.

14. Allender S, Wickramasinghe K, Goldacre M, Matthews D, Katulanda P. Quantifying urbanization as a risk factor for noncommunicable disease. J Urban Health. 2011;88(5):906-18. doi:10.1007/s11524-11011-19586-11521.

15. Galea S, Vlahov D. Urban health: evidence, challenges, and directions. Annu Rev Public Health. 2005;26:341-65. 
16. Chen M, Zhang H, Liu W, Zhang W. The global pattern of urbanization and economic growth: evidence from the last three decades. PLoS One. 2014;9(8):e103799.

17. Seubsman SA, Kelly MJ, Yiengprugsawan V, Sleigh AC. Gender, socioeconomic status, and self-rated health in a transitional middle-income setting: evidence from Thailand. Asia Pac J Public Health. 2011;23(5):754-65.

18. Aekplakorn W, Inthawong R, Kessomboon P, Sangthong R, Chariyalertsak S, Putwatana P, et al. Prevalence and trends of obesity and association with socioeconomic status in Thai adults: national health examination surveys, 1991-2009. J Obes. 2014:2014:8.

19. Aekplakorn W, Chariyalertsak S, Kessomboon P, Sangthong R, Inthawong R, Putwatana $\mathrm{P}$, et al. Prevalence and management of diabetes and metabolic risk factors in Thai adults: the Thai National Health Examination Survey IV, 2009. Diabetes Care. 2011:34(9):1980-5.

20. Angkurawaranon C, Lerssrimonkol C, Jakkaew N, Philalai T, Doyle P, Nitsch D. Living in an urban environment and non-communicable disease risk in Thailand: does timing matter? Health Place. 2015;33:37-47.

21. Batty GD, Alves JG, Correia J, Lawlor DA. Examining life-course influences on chronic disease: the importance of birth cohort studies from low- and middleincome countries. An overview. Braz J Med Biol Res. 2007:40:1277-86.

22. Sleigh AC, Seubsman SA, Bain C. Cohort profile: the Thai cohort of 87134 open university students. Int J Epidemiol. 2008;37(2):266-72.

23. S-a S, Kelly M, Sleigh A, Peungson J, Chokkanapitak J, Vilainerun D. Methods used for successful follow-up in a large scale national cohort study in Thailand. BMC Res Notes. 2011:4(1):166.

24. Thongtong P, Angkurawaranon C, Yavichai S, Thammasarot J, Bangsinthu S. Health survey of personnel in faculty of medicine, Chiang Mai university. Chiang Mai Med J. 2008;47(Suppl3):29.

25. Charuruks N, Milintagas A, Watanaboonyoungcharoen P, Kalayanachati A Nuchprayoon S. Annual laboratory checkup: early signs of health problems in young and middle-age adults. Southeast Asian J Trop Med Public Health. 2005;36(3):769-74.

26. Angkurawaranon C, Wisetborisut A, Jiraporncharoen W, Likhitsathian S, Uaphanthasath R, Gomutbutra P, et al. Chiang Mai University Health Worker Study aiming toward a better understanding of noncommunicable disease development in Thailand: methods and description of study population. Clin Epidemiol. 2014;6:277-86.

27. Zhao J, Seubsman SA, Sleigh A, Thai Cohort Study Team T. Timing of urbanisation and cardiovascular risks in Thailand: evidence from 51936 members of the Thai cohort study, 2005-2009. J Epidemiol. 2014;24(6):484-93.

28. Goldstein S, Goldstein A. Thailand's urban population reconsidered. Demography. 1978;15(3):239-58.

29. Kanazawa M, Yoshiike N, Osaka T, Numba Y, Zimmet P, Inoue S. Criteria and classification of obesity in Japan and Asia-Oceania. Asia Pac J Clin Nutr. 2002;11:S732-7.

30. American Diabetes Association. Diagnosis and classification of diabetes mellitus. Diabetes Care. 2008;31(Supplement 1):S55-60.

31. Kinra S, Andersen E, Ben-Shlomo Y, Bowen L, Lyngdoh T, Prabhakaran D, et al. Association between urban life-years and cardiometabolic risk: the Indian migration study. Am J Epidemiol. 2011;174(2):154-64.

32. Lim L, Kjellstrom T, Sleigh A, Khamman S, Seubsman SA, Dixon J, Banwell C. Associations between urbanisation and components of the health-risk transition in Thailand. A descriptive study of 87,000 Thai adults. Glob Health Action 2009, 2. doi: 10.3402/gha.v2i0.1914.

33. Banwell C, Lim L, Seubsman SA, Bain C, Dixon J, Sleigh A. Body mass index and health-related behaviours in a national cohort of 87134 Thai open university students. J Epidemiol Community Health. 2009;63(5):366-72

34. Lim L, Seubsman SA, Sleigh A. Validity of self-reported weight, height, and body mass index among university students in Thailand: Implications for population studies of obesity in developing countries. Popul Health Metrics. 2009;7(1):15

35. Wang Y, Lobstein TIM. Worldwide trends in childhood overweight and obesity. Int J Pediatr Obes. 2006;1(1):11-25.

36. Freedman DS, Khan LK, Serdula MK, Dietz WH, Srinivasan SR, Berenson GS. The relation of childhood BMI to adult adiposity: the Bogalusa heart study. Pediatrics. 2005;115(1):22-7.

37. Felber JP, Golay A. Pathways from obesity to diabetes. Int J Obes Relat Metab Disord. 2002;26 Suppl 2:S39-45
38. Cyril S, Oldroyd JC, Renzaho A. Urbanisation, urbanicity, and health: a systematic review of the reliability and validity of urbanicity scales. BMC Public Health. 2013;13:513. doi:10.1186/1471-2458-1113-1513.

39. Deepa M, Anjana RM, Manjula D, Narayan KMV, Mohan V. Convergence of prevalence rates of diabetes and cardiometabolic risk factors in middle and Low income groups in urban India: 10-year follow-Up of the Chennai urban population study. J Diabetes Sci Technol. 2011;5(4):918-27.

40. Sacks DB. A1C versus glucose testing: a comparison. Diabetes Care. 2011;34(2):518-23

41. Swinburn BA, Metcalf PA, Ley SJ. Long-term (5-year) effects of a reduced-Fat diet intervention in individuals with glucose intolerance. Diabetes Care. 2001;24(4):619-24.

42. Wing RR, Goldstein MG, Acton KJ, Birch LL, Jakicic JM, Sallis JF, et al. Behavioral science research in diabetes: lifestyle changes related to obesity, eating behavior, and physical activity. Diabetes Care. 2001;24(1):117-23.

43. Truesdale KP, Stevens J, Cai J. The effect of weight history on glucose and lipids: the atherosclerosis risk in communities study. Am J Epidemiol. 2005;161(12):1133-43.

44. Sodjinou R, Agueh V, Fayomi B, Delisle H. Obesity and cardio-metabolic risk factors in urban adults of Benin: relationship with socio-economic status, urbanisation, and lifestyle patterns. BMC Public Health. 2008;8(1):84.

45. Aekplakorn W, Kessomboon P, Sangthong R, Chariyalertsak S, Putwatana P, Inthawong R, et al. Urban and rural variation in clustering of metabolic syndrome components in the Thai population: results from the fourth national health examination survey 2009. BMC Public Health. 2011;11(1):854.

46. Darnton-Hill I, Nishida C, James WPT. A life course approach to diet nutrition and the prevention of chronic diseases. Public Health Nutr. 2004;7(1a):101-21.

47. Rerkasem K, Wongthanee A, Rerkasem A, Chiowanich P, Sritara P, Pruenglampoo $\mathrm{S}$, et al. Intrauterine nutrition and carotid intimal media thickness in young Thai adults. Asia Pac J Clin Nutr. 2012;21(2):247-52.

48. Winichagoon P. Thailand nutrition in transition: situation and challenges of maternal and child nutrition. Asia Pac J Clin Nutr. 2013;22(1):6-15.

49. Power C, Thomas C. Changes in BMl, duration of overweight and obesity, and glucose metabolism: 45 years of follow-up of a birth cohort. Diabetes Care. 2011;34(9):1986-91.

\section{Submit your next manuscript to BioMed Central and take full advantage of:}

- Convenient online submission

- Thorough peer review

- No space constraints or color figure charges

- Immediate publication on acceptance

- Inclusion in PubMed, CAS, Scopus and Google Scholar

- Research which is freely available for redistribution 